\title{
Mucho Ruido y pocos... DESC. Análisis del Caso Gonzales Lluy y Otros contra ECUADOR De la Corte INTERAMERICANA de Derechos Humanos
}

\author{
Much Ado About... ESCR. An Analysis of the Case 'Gonzales Lluy \\ et al. v. Ecuador' at the Inter-American Human Rights Court
}

\author{
Liliana Ronconi \\ Universidad de Buenos Aires, Argentina
}

Abogada y Profesora en Ciencias Jurídicas de la Universidad de Buenos Aires (UBA) y Doctoranda en la misma universidad. Becaria de Doctorado CONICET. Investigadora adscripta al Instituto de Investigaciones Jurídicas “A. L. Gioja”, Facultad de Derecho, UBA. Profesora Adjunta Regular de "Derechos Humanos", UNPAZ. Auxiliar Docente Derecho Constitucional, Facultad de Derecho, UBA. Imronconi@gmail.com.

\section{RESUMEN}

El propósito de este trabajo es reconstruir la línea argumentativa utilizada por la Corte Interamericana de Derechos Humanos en la resolución del caso Gonzales Lluy y otros versus Ecuador, de 1 de septiembre de 2015, conforme la tesis de que la Corte IDH aplica el argumento de igualdad en la versión del examen de proporcionalidad estricto como eje central de su argumentación, dejando de lado un posible argumento basado en el "principio de no regresividad". Sostengo que la decisión de la Corte IDH se asienta, fundamentalmente, en el trato discriminatorio que sufrió la demandante y su familia al poner en riesgo su vida y su integridad física y su derecho a la educación. Sin embargo, para muchos de los que trabajamos en DESC, el fallo es insuficiente, pues la Corte elude la aplicación del artículo 26 de la Convención Americana de Derechos Humanos (principio de progresividad y no regresividad). La aplicación y el desarrollo de los estándares contenidos en el artículo 26 de la $\mathrm{CADH}$ resultan de gran utilidad práctica para los diferentes Estados de la región, generando pautas interpretativas para la exigibilidad de los DESC y otorgando herramientas concretas para evaluar su incumplimiento.

Palabras clave

Derechos sociales; derecho a la educación; igualdad; Corte IDH.

\begin{abstract}
The aim of this paper is to retrace the line of argument deployed by the Inter-American Court of Human Rights in its ruling on the case 'Gonzales Lluy et al. v. Ecuador' on 1 September 2015, according to which, 'the Inter-American Court of Human Rights uses the equality principle as its main argument in the application of the strict scrutiny test, overlooking the use of the nonregression principle as a potential argument'. I suggest that the decision of the Court rested primarily on the discriminatory treatment suffered by the claimant and her family, jeopardizing her life, bodily integrity, and her right to education. However, for many of us working on ESCR, the ruling was not comprehensive enough, as the Court avoided the enforcement of Article 26 of the American Convention of Human Rights (principle of progressive development and nonregression clause). The application and development of the standards contained in Article 26 of
\end{abstract}


Liliana Ronconi

Mucho ruido y pocos... DESC. Análisis del caso Gonzales Lluy y Otros contra Ecuador de la Corte Interamericana de Derechos Humanos

the Convention are, however, of great practical use to the countries in the region, as they offer interpretive guidelines for the enforceability of ESCR, and provide practical tools to evaluate their breach.

\section{KEY WORDS}

Social rights; education right; equality; IACHR.

\section{INTRODUCCIÓN}

El 1 de septiembre del 2015, la Corte Interamericana de Derechos Humanos (Corte IDH) resolvió el caso Gonzales Lluy y otros versus Ecuador ${ }^{1}$. El caso es paradigmático en el sentido de que se convirtió en el primer pronunciamiento de la Corte IDH respecto de la violación del Protocolo de San Salvador (PSS), como asimismo de la aplicación del concepto de discriminación interseccional. En este trabajo me propongo reconstruir la línea argumentativa de la Corte IDH, siguiendo la siguiente tesis: "la Corte IDH aplica el argumento de igualdad en la versión del examen de proporcionalidad estricto como eje central de su argumentación, dejando de lado un posible argumento basado en el principio de no regresividad". Sostengo que la decisión de la Corte IDH se asienta, fundamentalmente, en el trato discriminatorio individual que sufrió la demandante y su familia al poner en riesgo su vida y su integridad física y su derecho a la educación. Sin embargo, para muchos de los que trabajamos DESC el fallo se queda a mitad de camino, pues la Corte parece eludir la aplicación del artículo 26 (principio de progresividad y no regresividad $)^{2}$.

El trabajo se dividirá en las siguientes partes: en primer lugar (I) me referiré a los hechos del caso. Luego (II) analizaré los argumentos presentes en la argumentación de la Corte IDH, en lo que respecta al (1) derecho a la vida e integridad física y al (2) derecho a la educación. Esto me permitirá (III) problematizar sobre aquellos argumentos que quedaron afuera y que eran importantes no solo para el caso en cuestión sino para sostener la consolidación de la justiciabilidad de los DESC en la Corte IDH ${ }^{3}$. Por último, (IV) concluiré que la Corte ha dejado pasar una nueva oportunidad de aplicar el artículo 26 de la Convención Americana de Derechos Humanos (CADH). La aplicación

1 Corte IDH. Caso Gonzales Lluy y otros vs. Ecuador. Sentencia de 1 de septiembre de 2015 (excepciones preliminares, fondo, reparaciones y costas). Serie C No 298 .

2 Courtis, Christian (2014). "Artículo 26. Desarrollo progresivo". En: Steiner, Christian y Patricia URIBE (ed.) Convención Americana sobre Derechos Humanos. Comentario, Fundación Konrad Adenauer, La Paz: Plural Editores, pp. 654-676.

3 El objetivo del artículo no es hacer una retrospectiva de la jurisprudencia de la Corte IDH en materia de derechos sociales. Al respecto, entre otros, véase, Rossi, Julieta y Víctor ABRAmovich (2009). "La tutela de los derechos económicos, sociales y culturales en el artículo 26 de la Convención Americana sobre Derechos Humanos", Revista Estudios Socio-Jurídicos 9: 34-53; KRSTICEvic, Viviana (2006). "La tutela de los derechos sociales en el sistema interamericano". En: Yamin, Alicia (coord.). Derechos económicos, sociales y culturales en América Latina. Del invento a la herramienta. Centro Internacional de Investigaciones para el Desarrollo/Asociación Pro Derechos Humanos, México D.F.: Plaza y Valdés Editores, pp. 171-194; PARRA VERA, Oscar (2013). "La protección del derecho a la salud a través de casos contenciosos ante el Sistema Interamericano de Derechos Humanos". En: Clérico, Laura, Liliana Ronconi y Martín Aldao. Tratado de Derecho a la salud. Tomo I. Buenos Aires: Abeledo Perrot, pp. 761-799. 
de esta norma no es solo una cuestión dogmática, sino que es una herramienta potente para la resolución de casos similares, en el ámbito regional y local latinoamericano.

\section{HeCHOS}

La demandante Talía Gabriela Gonzales Lluy tenía tres años de edad cuando fue contagiada con el virus de VIH al recibir una transfusión de sangre, el 22 de junio de 1998, proveniente de un banco de Sangre de la Cruz Roja, en una clínica privada de salud. Se determinó que la sangre transfundida a Talía estaba contagiada con el virus y no había sido (suficientemente) analizada en el banco de sangre ni en la clínica. Al conocer esto, la madre de la niña presentó varios recursos en instancias civiles y penales en Ecuador. En estas los peritos concluyeron que "desde el punto de vista de la lógica médica, que la única vía de propagación del VIH hacia la niña [Talía] es la transfusión sanguínea" (considerando 105). La acción penal para condenar a los responsables del contagio se declaró prescrita en el 2005 por no haber podido capturar a la imputada (agente a cargo del control de las muestras en el banco de sangre) durante el tiempo transcurrido desde que se cometió el delito investigado. La acción civil para reclamar los daños y perjuicios ocasionados por el contagio de VIH a Talía fue declarada nula (el 18 de mayo de 2006), ya que la Primera Sala de la Corte Superior de Justicia de Cuenca determinó que al no existir sentencia penal, no se cumplía con un requisito indispensable para admitir la acción civil y, por tanto, todo lo actuado era nulo (considerando131).

Más allá de las idas y venidas judiciales, la vida de Talía y su familia sufrió un fuerte impacto desde el contagio de VIH a la niña. A saber:

- Afectación en la salud de Talía y en la de su familia: luego de contraer la enfermedad Talía debía realizarse estudios, tomar medicación, asistir a visitas médicas en hospitales o lugares alejados de su domicilio donde no recibía ningún tipo de trato especial por su situación. Su familia, debido a los esfuerzos para sobrellevar la situación, padeció enfermedades crónicas, entre otras afectaciones.

- Situación de pobreza de la familia: la situación económica de la familia era crítica. El padre desapareció un tiempo después de conocer la situación de Talía. La madre, cuando se hizo pública la enfermedad de Talía, fue despedida de su trabajo en la empresa en la que había trabajado por más de 10 años, por "dar una mala imagen a la misma". Se vio obligada a realizar trabajos domésticos que también perdía cuando sus empleadores conocían la situación de su hija. A esto se sumaban los diversos esfuerzos para que Talía recibiera atención médica, medicamentos, concurrencia a controles médicos varios, entre otros. La falta de entrega de medicamentos y pago de tratamientos obligó a la familia a vender sus pocas pertenencias. Fueron obligadas a mudarse en múltiples ocasiones, debido a la exclusión y el rechazo del que fueron objeto, a lugares alejados donde pudieran encontrar una vivienda o una escuela que aceptara a la niña.

- Derecho a la educación de Talía: en 1999 cuando Talía tenía 5 años fue anotada en la escuela pública de la Ciudad de Cuenca cerca de donde vivía con su familia. A los dos meses, cuando las autoridades (maestra, director) conocieron la enfermedad de la niña se decidió que Talía no asistiera más a clases hasta que las autoridades adoptaran una "solución al problema" (considerando 133). En ese tiempo asistieron funcionarios de la Dirección de Salud y explicaron acerca de la "imposibilidad de 
contagio", sin embargo el director del establecimiento decidió apartar definitivamente a la niña y entregar sus papeles de "desglose". Se alegó "un inminente riesgo en contra de los educandos", ya que Talía había tenido varias hemorragias y también porque en el primer año se trabajaba con objetos cortopunzantes (considerando 135/8). Esta decisión fue confirmada por el Tribunal Distrital de lo Contencioso $\mathrm{N}^{\circ} 3$ alegando que ante tal conflicto de intereses predominan los sociales o colectivos del conglomerado estudiantil frente al derecho a la educación de Talía (considerando 141). Además, se argumentó que la niña podía ejercer su derecho a distancia.

\section{Argumentos de la Corte IDH}

La Corte IDH considera que en el caso bajo análisis se violaron múltiples derechos de Talía y su familia, conforme los argumentos que a continuación se analizan ${ }^{4}$ :

\section{Violación del Derecho a la vida y a la integridad personal}

La Corte IDH recordó la fuerte interdependencia existente entre los derechos civiles y políticos y los derechos económicos, sociales y culturales, reconociendo que no basta con que los Estados se abstengan de violar los derechos sino que además deben adoptar medidas positivas, en función de las particulares necesidades del sujeto de derecho. Asimismo, reconoce que los Estados no son responsables por los hechos de terceros pero afirma que tienen un deber de impedir que terceros interfieran indebidamente en el goce de los derechos (deber de regular/ fiscalizar). En este sentido, y si bien la transfusión de Talía fue realizada en instituciones privadas, la Corte IDH consideró la existencia de violación al derecho a la vida y a la integridad personal de Talía por no haber ejercido controles suficientes respecto de tales agentes. La precariedad e irregularidades en las que funcionaba el Banco de Sangre permitieron que sangre que no había sido sometida a los exámenes de seguridad más básicos como el de VIH fuera entregada a la familia de Talía para la transfusión de sangre, con el resultado de su infección y el consecuente daño permanente a su salud. Por esto, la Corte IDH considera violados los artículos 4 y 5 de la $\mathrm{CADH}^{5}$.

Asimismo, la Corte IDH consideró que en el caso existió una violación al derecho a la integridad personal de la familia de Talía, su madre Teresa Lluy y su hermano Iván Lluy. Los esfuerzos por atender a Talía y la situación de discriminación que padecían llevaron a la enfermedad de la madre (diabetes emocional, hipertensión, dolores físicos crónicos). Iván debió salir a trabajar siendo un adolescente, dejó el colegio y fue diagnosticado con depresión. Por esto, la Corte reconoce la violación al derecho a la integridad física de los familiares directos de Talía. Nuevamente en este punto se verifica una ausencia o insuficiencia de los deberes del Estado de acompañar a la familia para superar la precaria situación económica como el estigma social que padecían.

4 La Corte IDH se refiere también a la violación al artículo 8 de la CADH (garantías judiciales y protección judicial), sin embargo no se toma en cuenta en este trabajo.

5 La actora también alegaba la violación de los artículos 4 y 5 de la CADH por la falta o la insuficiente disponibilidad de atención médica, la entrega de medicamentos antirretrovirales e información acerca de la enfermedad. La Corte consideró que la prueba existente no era suficiente para condenar al Estado. 


\section{Violación del derecho a la educación}

En varias oportunidades Talía fue desplazada de distintas escuelas ${ }^{6}$ alegando la supuesta protección a la salud e integridad física de la comunidad académica ${ }^{7}$. La Corte considera que existió una violación del derecho a la educación (artículo 13 PSS) de la niña, a base de los siguientes argumentos ${ }^{8}$ :

\section{a) La especial situación de Talía otorga mayor preponderancia al derecho} a la educación

El derecho a la educación ha sido y se ha caracterizado como un derecho-llave, pues permite el acceso a otros derechos. En este sentido, no solo contribuye al pleno desarrollo de la personalidad humana, sino también permite el desarrollo o disfrute de otros derechos individuales y colectivos ${ }^{9}$.

Esta caracterización cobra especial relevancia cuando se trata de la afectación del derecho a la educación de una persona perteneciente a un grupo históricamente discriminado como es el caso de Talía por ser portadora de VIH. En este sentido, "las personas con VIH han sido históricamente discriminadas debido a las diferentes creencias sociales y culturales que han creado un estigma alrededor de la enfermedad (...) que una persona viva con VIH/SIDA, o incluso la sola suposición de que lo tiene, puede crear barreras sociales y actitudinales para que esta acceda en igualdad de condiciones a todos sus derechos" (considerando 236). La educación debe ser una herramienta que permita por un lado obtener, garantizar información (libre de prejuicios) sobre el VIH. En este punto, entonces, el derecho a la educación tiene un estrecho vínculo con la autonomía ${ }^{10}$.

6 O bien, directamente no era recibida.

7 De hecho, conforme la declaración de la propia Talía, en las audiencias ante la CorteIDH, ella puede terminar su educación gracias a la buena voluntad de las autoridades de una institución que negaban a las autoridades de Educación que ella estuviera cursando allí. Disponible en: https://vimeo.com/125630336 [consulta: 15 de febrero de 2016].

8 La Corte IDH tuvo oportunidad de referirse al derecho a la educación en otros casos (véanse, caso Yean y Bosico vs. República Dominicana. Sentencia 8 de septiembre de 2005 (excepciones preliminares, fondo, reparaciones y costas). Serie C No 130 y caso Comunidad Indígena Xákmok Kásek. vs. Paraguay. Sentencia de 24 de agosto de 2010 (fondo, reparaciones y costas). Serie C N 214). Sin embargo, estos casos fueron resueltos por la violación a la vida digna (por falta de acceso a la documentación o a la tierra) y no por violación al derecho a la educación.

9 De esta manera, sostiene Tomasevsky, el derecho a la educación es un derecho multiplicador que, cuando está garantizado, aumenta el disfrute de todos los demás derechos, mientras que cuando se niega impide el disfrute de los otros derechos. Tomasevsky, Katarina (2004). El asalto a la educación Barcelona: Itermon Oxfam, p. 13.

10 En este sentido, sostiene Nino que "por un lado, la educación es escencial para la posibilidad de elegir libremente planes de vida e ideales del bien. Por el otro lado, una determinada educación es necesaria para materializar el plan de vida o el ideal del bien libremente elegido. Nino, Carlos (2005). Fundamentos de Derecho Constitucional ( $3^{\circ}$ reimp.). Buenos Aires: Astrea, p. 293. Destaca la Corte IDH "la importancia que tiene la educación en el objetivo de reducir la vulnerabilidad de los niños con VIH/SIDA, mediante la facilitación de información pertinente y apropiada que contribuya a mejorar el conocimiento y comprensión del VIH/SIDA, así como impedir la manifestación de actitudes negativas respecto de las personas con VIH/SIDA y a eliminar las prácticas discriminatorias. En el caso de las niñas y los niños con VIH/SIDA, es necesario que los Estados tomen medidas para que estos tengan acceso a la educación sin limitaciones" (considerando 278). 
Liliana Ronconi

Mucho ruido y pocos... DESC. Análisis del caso Gonzales Lluy y Otros contra Ecuador de la Corte Interamericana de Derechos Humanos

Por otro lado, una herramienta que permita la integración y la convivencia democrática. En este sentido, el derecho a la educación implica mucho más que el mero hecho de aprender determinados contenidos mínimos. El derecho a la educación implica garantizar las bases para la convivencia democrática. Sostiene Guttman que la educación refuerza la democracia pues permite desarrollar la capacidad de deliberar en los niños y las niñas, como futuros ciudadanos/as libres e iguales, así, "los valores que la deliberación implica incluyen veracidad, no violencia, criterio práctico, integirdad cívica y magnanimidad. Promoviendo estos y otros valores y capacidades deliberativas, una sociedad democrática puede asegurar las oportunidades básicas a los ciudadanos, así como su capacidad colectiva de obtener justicia"11. De esta manera, no puede lograrse la integración si existen grupos o personas que son separadas del resto. Esto me lleva al siguiente punto.

\section{b) El estrecho vínculo entre educación e igualdad: el examen de proporcionalidad}

Talía fue apartada de la escuela a base de su condición de salud. El hecho desencadenante fue la noticia de que Talía estaba contagiada de VIH, aunque asintomática. De esta manera, es posible imaginar la existencia de dos grupos: aquel conformado por las personas (niños/as) que no tienen VIH y pueden asistir a la escuela, y aquel formado por personas con VIH que no pueden asistir a la escuela, grupo del que formaría parte Talía. No existía en el caso una norma que impedía a las personas con VIH asistir a la escuela, sino que esto se originó en las acciones de las autoridades educativas/ judiciales.

Ahora bien, cuando hablamos de igualdad es conocido el argumento de que las diferencias de trato no están prohibidas, siempre que estén justificadas, sean razonables y objetivas y en orden a determinar la legitimidad de una medida es posible aplicar el examen de proporcionalidad ${ }^{12}$. De esta manera, toda medida que implique una distinción debe pasar los subexámenes de idoneidad, necesidad y proporcionalidad en sentido estricto $^{13}$. En el caso particular que estoy analizando, la diferencia de trato a la que ha sido sometida Talía y su familia se asienta sobre una categoría sospechosa: la condición de persona con VIH como aspecto potencialmente generador de discapacidad (considerando 255) ${ }^{14}$. La existencia de una categoría sospechosa como base de la distinción exige la aplicación de un examen estricto de igualdad. ¿Qué implica? Por

11 Guttman, Amy (2001). La educación democrática. Una teoría política de la educación. Barcelona: Paidós, p. 15. Es por esto que continuar los estudios "a distancia" no era una opción viable en este caso.

12 La Corte IDH aplicó este juicio en los casos Kimel vs. Argentina Sentencia de 2 de mayo de 2008 (fondo, reparaciones y costas). Serie C N 177 y Atala Riffo y niñas vs. Chile. Sentencia de 24 de febrero de 2012 (fondo, reparaciones y costas) Serie $\mathrm{C} \mathrm{N}^{\circ} 239$, entre otros.

13 La definición de los tres subprincipios de la proporcionalidad en el Derecho constitucional se debe en principio a la jurisprudencia del Tribunal Constitucional alemán. Para mayor amplitud véase Alexy, Robert (1993). Teoría de los derechos fundamentales [traducción de Ernesto Garzón Valdés], Madrid: Centro de Estudios Constitucionales; Bernal Pulido, Carlos (2007). El principio de proporcionalidad y los derechos fundamentales, $3^{\text {a }}$ edición, Madrid: Centro de Estudios Políticos y Constitucionales; CLÉRICO, Laura (2009). El examen de proporcionalidad en el Derecho constitucional. Buenos Aires: editorial Eudeba/ Departamento de Publicaciones de la Facultad de Derecho de la Universidad de Buenos Aires.

14 Esto fue sostenido anteriormente por la Corte IDH respecto de la “orientación sexual”. Véase, al respecto, caso Atala Riffo y niñas vs. Chile. Asimismo, Von Bogdandy, Armin, Flávia Piovesan y Mariela Morales Antoniazzi (coord.) (2012). Igualdad y orientación sexual. El Caso Atala de la Corte Interamericana de Derechos Humanos y su potencial. México DF: Porrúa. 
un lado, que la carga de la argumentación queda en cabeza del Estado y, por otro, que las razones alegadas por el Estado para justificar la distinción deben ser de un peso alto, extraordinario (análisis estricto de razonabilidad) ${ }^{15}$.

Aplicando este test, la Corte IDH analiza si el medio adoptado, esto es, el impedimento de que Talía asista a clases guarda relación de medio a fin con el objetivo perseguido por el Estado, consistente en proteger el derecho a la vida, la integridad física y la salud de la comunidad académica (niños/as y docentes). La pregunta que sigue es si existe dicha relación intensa/estrecha entre medio y fin. La respuesta negativa se impone poniendo en evidencia que el accionar de los distintos agentes educativos y judiciales se basa en una única circunstancia concreta: prejuicios y estigmas respecto de la situación de Talía. En este sentido, "si se estipula una diferencia de trato en razón de la condición médica o enfermedad, dicha diferencia de trato debe hacerse a base de criterios médicos y la condición real de salud tomando en cuenta cada caso concreto, evaluando los daños o riesgos reales y probados, y no especulativos o imaginarios. Por tanto, no pueden ser admisibles las especulaciones, presunciones, estereotipos o consideraciones generalizadas sobre las personas con VIH/SIDA o cualquier otro tipo de enfermedad" (considerando 258).

En primer lugar es necesario efectuar el análisis de proporcionalidad, comenzando por el primero de los subexámenes, esto es la idoneidad del medio. La pregunta que sigue, entonces, es: ¿constituye la exclusión de Talía de la escuela un medio idóneo para proteger el derecho a la vida, integridad física y salud de la comunidad educativa? No, pues no existió una prueba concreta del daño que podría acarrear la salud de Talía para el resto de la comunidad educativa. El interés superior del niño no puede ser invocado en forma abstracta y genérica ${ }^{16}$, más aun cuando la violación al derecho de Talía es total. La identificación del riesgo de la comunidad académica debía fundarse en criterios médicos atendiendo a lo especializado del análisis para establecer el peligro o riesgo supuesto que se cernía sobre los estudiantes de la escuela (considerando 272). Esto es así ya que cuando se aplica la fórmula de la proporcionalidad en forma intensiva no alcanza con que lo fomente de alguna forma, tiene que existir una relación de fomento bien cercana ${ }^{17}$. En el caso, el medio (exclusión de las escuelas) es inidóneo, pues ha sido seleccionado en función de prejuicios y estereotipos discriminatorios relativos a la situación de Talía de estar contagiada de VIH y no a partir de una evaluación objetiva de los (pocos) riesgos que su situación implicaba para la comunidad académica.

De esta manera, nos encontramos frente a un caso claro de falta de proporcionalidad en sentido amplio de la distinción basada en el hecho de estar contagiada de VIH, ya

15 En este sentido, “cuanto más se interfiere en la realización de un derecho (...), dejándolo casi sin posibilidad de realización alguna, tanto más fuerte será su capacidad de resistencia, es decir, su peso, y la fuerza de las razones que pretenden justificar (esa falta de realización) deben crecer de forma 'más que proporcional' ('sobreproporcional'), de forma tal que una interferencia en ese ámbito pueda ser justificada". CLÉRICO, Laura (2010). "El matrimonio igualitario y los principios constitucionales estructurantes de igualdad y/o autonomía”. En: Clérico, Laura y Martín Aldao (coords.) Matrimonio igualitario en la Argentina. Perspectivas sociales, políticas y jurídicas, Buenos Aires: Eudeba, p. 154.

16 Corte IDH, Caso Atala Riffo y Niñas vs. Chile. Sentencia de 24 de febrero de 2012 (fondo, reparaciones y costas). Serie C N ${ }^{\circ}$ 239; Corte IDH, Caso Forneron e Hija us. Argentina (fondo, reparaciones y costas). Sentencia de 27 de abril de 2012. Serie C No 242.

17 Para mayor amplitud, véase ClérICO, 2009: 59 ss. 
Liliana Ronconi

Mucho ruido y pocos... DESC. Análisis del caso Gonzales Lluy y Otros contra Ecuador de la Corte Interamericana de Derechos Humanos

que la medida no llega a superar siquiera el subexamen de idoneidad. Así, la medida tampoco era necesaria siendo que el único medio que fomenta el fin, sin vulnerar derechos, es garantizar la educación de Talía y de sus compañeros/as en condiciones adecuadas, con medidas de bioseguridad o similares para la prevención general de la transmisión de enfermedades (adaptabilidad, en términos de Tomasevsky) ${ }^{18}$. Sin embargo, el medio escogido ("una instrucción particularizada y a distancia") constituía la alternativa más lesiva y desproporcionada de las disponibles, pues implicaba la negación y total exclusión de una niña, pobre, con una grave enfermedad. En lo que respecta a la proporcionalidad en sentido estricto, queda demostrado que la violación al derecho a la educación (derecho-llave) es casi absoluta, en cambio no sucede lo mismo con el derecho a la vida, integridad y salud de la comunidad académica.

\section{c) La discriminación interseccional}

El caso bajo análisis es también paradigmático, ya que es la primera oportunidad en que la Corte IDH se refiere a la situación de discriminación interseccional ${ }^{19}$. En este sentido, sostiene que "la discriminación contra Talía ha estado asociada a factores como ser mujer, persona con VIH, persona con discapacidad, ser menor de edad, y su estatus socioeconómico. Estos aspectos la hicieron más vulnerable y agravaron los daños que sufrió" (considerando 285); y agrega que, sin embargo, "la discriminación que vivió Talía no solo fue ocasionada por múltiples factores, sino que derivó en una forma específica de discriminación que resultó de la intersección de dichos factores, es decir, si alguno de dichos factores no hubiese existido, la discriminación habría tenido una naturaleza diferente" (considerando 290).

La “discriminación interseccional” surge de una combinación de elementos que ocasiona un tipo de discriminación diferente de cualquier otra basada en un solo factor. Se trata de factores conexos que agravan la situación de vulnerabilidad. En este sentido, la "vulnerabilidad es una condición acumulativa: los sujetos desprotegidos se ven inmersos en ocasiones en una 'espiral de la vulnerabilidad'. Se llama espiral de vulnerabilidad a la circunstancia en virtud de la cual a una condición de vulnerabilidad inicial (vejez, discapacidad, minoría de edad), se suma otra, debida a condiciones económicas de pobreza, o condiciones culturales de pertenencia a un grupo minoritario, tradicionalmente discriminado, lo que genera a su vez otras condiciones de vulnerabilidad" 20 . Esta imagen del espiral indica que las causas de discriminación operan en forma concurrente, conexa, produciendo un efecto sinérgico (superior a la suma simple de cada una de las causas de discriminación) que implica una experiencia muy particular de discriminación ${ }^{21}$. Este enfoque resulta útil a la hora de interpretar de manera integral una experiencia

18 Tomasevsky, Katarina (2004a). Indicadores del Derecho a la Educación. Revista del Instituto Interamericano de Derechos Humanos 40: 341-388.

19 Considerando 290. La utilización incipiente de este concepto puede verse en la citada sentencia de la Corte IDH, caso Yean y Bosico vs. República Dominicana.

20 Mosquera Quintero, Diana (2011). La salud como derecho. Estudio comparado sobre grupos vulnerables. Bogotá: Siglo del Hombre/ Universidad ICESI/ Red ALAS, p. 84.

21 Góngora Mera, Manuel (2013). "Derecho a la salud y discriminación interseccional: Una perspectiva judicial de experiencias latinoamericanas”. En: CléRICO, Laura, Liliana Ronconi y Martín AldAo, Tratado de Derecho a la Salud, Buenos Aires: Abeledo Perrot, pp. 133-159. 
particular usualmente invisibilizada. Son casos donde no estaría ante el mismo supuesto en caso de que los factores de discriminación actuaran en forma individual.

Tomar en cuenta los distintos factores de discriminación que afectan la situación en la que se encuentran estos grupos es interesante, pues demuestra la insuficiencia de las políticas públicas unidireccionales (es decir, aquellas que atacan solo una de las causas de discriminación) y la necesidad de políticas integrales que erradiquen la desigualdad en todos sus aspectos.

\section{LOS ARGUMENTOS AUSENTES}

El análisis de los argumentos utilizados por la Corte IDH me permite cuestionar aquellos argumentos que no aparecieron, pero que habrían resultado necesarios para el otorgamiento de plena justiciabilidad a los DESC en el sistema interamericano, aún cuando quizá no tengan un efecto práctico en el caso concreto.

La discusión actual en torno a los DESC está muy vinculada no ya a su operatividad/ progamaticidad, sino ante todo a identificar criterios que permitan afirmar en los casos concretos que se está ante un supuesto de vulneración de derechos. Para esto, la aplicación y el desarrollo de los estándares contenidos en el artículo 26 de la CADH resultan de gran utilidad práctica, generando pautas interpretativas para la exigibilidad de los DESC y otorgando herramientas concretas para evaluar su incumplimiento. Sin embargo, esto no aparece en el desarrollo argumentativo de la Corte IDH en el caso bajo análisis. Veamos:

- Aplicación del estándar de No regresividad: la Corte IDH considera la violación del derecho a la vida e integridad física de Talía y su familia. Sin embargo, aquí aparece la primera insuficiencia. Lo que estaba en juego era sobre todo el derecho a la salud de Talía y su familia. Específicamente, la obligación que le corresponde al Estado (en virtud del artículo $26 \mathrm{CADH}$ ) de garantizar condiciones mínimas del derecho, de adoptar providencias para lograr la plena efectividad de la vigencia de tales derechos (principio de progresividad) y, correlativamente, "de la noción de desarrollo progresivo se desprende un deber condicionado de no regresividad, que requiere del Estado una justificación estricta en caso de adopción de medidas regresivas"22. Estos supuestos son de fácil verificación en el caso: (i) el Estado no garantizó las condiciones mínimas para realizar transfusiones de sangre seguras y esto es contrario a la obligación de no regresividad y progresividad, que implican la garantía de acceder a los servicios básicos de salud en condiciones de seguridad; (ii) el reconocimiento de la violación directa al derecho a la salud (no vía un derecho clásico) requiere necesariamente la determinación de las obligaciones concretas del Estado en la materia. Este reconocimiento podría tener efecto en las acciones posteriores del resto de los Estados de la región, al conocer de antemano cuáles son los parámetros con los que se evaluarán sus acciones (u omisiones). La garantía de no regresividad implica que el Estado no debe volver atrás en el reconocimiento de un derecho. En el caso, la afectación al derecho a la salud de Talía y su familia se

22 Courtis, 2014: 660. 
Liliana Ronconi

Mucho ruido y pocos... DESC. Análisis del caso Gonzales Lluy y Otros contra Ecuador de la Corte Interamericana de Derechos Humanos

verifica por violación a esta garantía: el Estado no cumplió con su deber de contralar implicando, por lo tanto, varios pasos atrás ${ }^{23}$ en el desarrollo de sus obligaciones.

- Aplicación del estándar de “contenido mínimo”, en cuanto al derecho a la educación, la aplicación del examen de igualdad para resolver un caso tan claro de negación de un derecho deja ciertas dudas, ya que lo que está en juego es el contenido mínimo 24 del derecho. El derecho a la educación básica y elemental también actúa como regla ${ }^{25}$. Esto implica que no puede negarse en ningún caso el derecho a asistir a un establecimiento educativo para recibir educación, más aun cuando se trata de una niña pobre con VIH. Lo que está en juego entonces es aquel contenido básico del derecho que no se puede ponderar frente a otros principios ${ }^{26}$. Respecto de ciertos grupos, como ya sostuve, la educación adquiere mayor preponderancia. Es LA herramienta que permitirá la inclusión. Es por esto que no puede haber ningún justificativo para dejar a un niño/a fuera de la escuela. Este es el impacto de la resolución del caso por aplicación de un estándar internacional distinto al del principio de igualdad. La obligación de garantizar el derecho a la educación no es solo respecto de Talía sino respecto de todos/as aquellos/as niños/as que se encuentran por diversas causas excluidos del acceso a la educación.

Así las cosas, el caso debía resolverse por violación de contenido mínimo (negación lisa y llana del derecho) y no por un argumento de igualdad. Aún más, respecto de este argumento. Abordar del caso por trato discriminatorio parece mostrar que se trata de un caso aislado de violación de DESC, cuando en el contexto latinoamericano la falta de acceso o goce de los derechos sociales para las poblaciones más vulnerables indica que es necesario reforzar el reconocimiento de estos derechos y las obligaciones del Estado en la materia. Como la propia Corte reconoce, la niña no solo padeció de discriminación por estar contagiada de VIH, sino principalmente por falta de acceso a los derechos sociales básicos por parte de Talía (salud, educación, vivienda) y su familia (salud, vivienda, derechos laborales, entre otros). No se trata entonces de un caso individual de violación, sino de la situación en la que se encuentran los DESC en el país. La aplicación de un estándar mucho más exigente como el del "contenido mínimo" pondría al país denunciado e incluso al resto de los países de la región, en

23 CouRtis, Christian (comp.) (2006). Ni un paso atrás. La prohibición de regresión en materia de derechos sociales. Buenos Aires: Del Puerto.

24 Ronconi, Liliana (2012). "Derecho a la salud: Un modelo para la determinación de los contenidos mínimos y periféricos". Revista Salud Colectiva, 8 (2): 131-149. Disponible en http://www.scielo.org.ar/pdf/sc/v8n2/ v8n2a03.pdf> [consulta: 15 de febrero de 2016].

25 Comité DESC, Observación General N 3. $21^{\circ}$ período de sesiones, 1999. U.N. Doc. E/C.12/1999/10. Asimismo, Scioscioli, Sebastián (2015). La educación básica como derecho fundamental. Implicancias y alcances en el contexto de un Estado federal. Buenos Aires: Eudeba.

26 El principio de progresividad y de no regresividad deben ser ponderados frente a otros principios (al respecto, Corte IDH. Casos Cinco Pensionistas vs. Perú. Sentencia de 28 de febrero de 2003 (fondo, reparaciones y costas). Serie C N 98 y Acevedo Buendía y Otros (Cesantes y Jubilados de la Contraloría) vs. Perú. Sentencia de 1 de julio de 2009 (excepción preliminar, fondo, reparaciones y costas). Serie C No 198). Asimismo, Parra Vera, Oscar (2011). Justiciabilidad de los derechos económicos, sociales y culturales ante el Sistema Interamericano, Comisión Nacional de Derechos Humanos, México; Clérico, Laura (2008). "Las otras caras de los derechos sociales: las obligaciones iusfundamentales y la desigualdad estructural". En: Asociación por los Derechos civiles. La Corte y los derechos 2005/2007. Cómo impactan en la vida de los ciudadanos las decisiones del máximo tribunal, Buenos Aires: Siglo XXI Editores, pp. 479-494. 
situación de conocimiento indubitable respecto de sus obligaciones en lo que respecta al derecho a la educación.

De esta manera, si bien para el caso particular los efectos en la utilización de unos u otros argumentos no reviste mayor importancia, la utilización de los argumentos indicados en este trabajo como ausentes resultaba relevante para los países de la región, ya que la discusión actual en torno a los DESC en el ámbito local no está vinculada tanto a si los mismos resultan exigibles o no, sino más bien a la forma de determinar cuando los mismos han resultado lesionados. En este sentido, la palabra de la Corte IDH indicando que la no garantía de transfusiones de sangre en forma segura es violatoria del derecho a la salud, implica un avance en la determinación de las obligaciones básicas de los Estados de la región respecto de ese derecho. Lo mismo sucede respecto del derecho a la educación. La posición de la Corte IDH asumiendo que la negación lisa y llana del derecho a la educación no admite prueba en contrario hubiera representado un gran avance en términos del contenido del derecho. Esta es la preponderancia que en el caso adquiría la aplicación del artículo 26 de la CADH.

\section{Conclusión}

La resolución de este caso por la Corte IDH resulta relevante en varios aspectos. La Corte realiza una buena conceptualización de la concepción de igualdad interseccional y sus implicancias. Reconoce, asimismo, al VIH como categoría de discriminación prohibida.

Sin embargo, lo más destacable del caso es que es la primera vez que se reconoce la plena justiciabilidad de un derecho social, el derecho a la educación, en clara aplicación del artículo 13 de PSS. Como es sabido, de los múltiples casos que han llegado a la Corte IDH muchos de ellos se vinculan con derechos sociales, sin embargo, la Corte, en general, no ha reconocido su violación, sino solo indirectamente como derecho asociado a un derecho civil o político clásico ${ }^{27}$. Esto puede deberse a la falta de competencia de la Corte en la materia, ya que en virtud del artículo 19 del PSS la Corte solo tiene competencia contenciosa en casos relativos a Derechos Sindicales o el Derecho a la educación. Sin embargo, considero que el artículo 26 de la CADH es muy potente como forma de protección directa del resto de los derechos sociales y que la Corte ha dejado pasar buenas oportunidades en su reconocimiento.

En este sentido, la resolución del caso en virtud del artículo 26 de la CADH hubiera resultado mucho más oportuna y abriría las puertas a la resolución de casos similares, en el ámbito regional como local, ya que la discusión actual gira en torno a la necesidad de determinar en los casos concretos si ha existido o no violación a un derecho social. Para conocer si existe violación, por negación del contenido mínimo, violación al principio de no regresividad o de progresividad se requiere el establecimiento de parámetros claros de referencia. En el caso, la voz de la Corte IDH indicando la afectación del derecho a la salud y a la educación por violación del artículo 26 de la CADH permitiría a los Estados contar con otro tipo de indicador de sus obligaciones en la materia.

27 La excepción puede encontrarse en los votos concurrentes del Juez Ferrer Mac Gregor. 


\section{Bibliografía}

Alexy, Robert (1993). Teoría de los derechos fundamentales [traducción de Ernesto Garzón Valdés], Madrid: Centro de Estudios Constitucionales.

Bernal Pulido, Carlos (2007). El principio de proporcionalidad y los derechos fundamentales, $3^{\text {a }}$ edición, Madrid: Centro de Estudios Políticos y Constitucionales.

ClÉRICO, Laura (2008). "Las otras caras de los derechos sociales: las obligaciones iusfundamentales y la desigualdad estructural". En: Asociación POR Los Derechos civiles. La Corte y los derechos 2005/2007. Cómo impactan en la vida de los ciudadanos las decisiones del máximo tribunal, Buenos Aires: Siglo XXI Editores, pp. 479-494.

(2009). El examen de proporcionalidad en el Derecho constitucional. Buenos Aires: editorial Eudeba/Departamento de Publicaciones de la Facultad de Derecho de la Universidad de Buenos Aires (tesis).

(2010). "El matrimonio igualitario y los principios constitucionales estructurantes de igualdad y/o autonomía". En: CLÉRICO, Laura y Martín ALDAO (coords.). Matrimonio igualitario en la Argentina. Perspectivas sociales, políticas y jurídicas, Buenos Aires: Eudeba, pp. 145-170.

CourTis, Christian (2014). "Artículo 26. Desarrollo progresivo". En: Steiner, Christian y Patricia Uribe (ed.). Convención Americana sobre Derechos Humanos. Comentario, Fundación Konrad Adenauer, La Paz: Plural editores, pp. 654-676.

(comp.) (2006). Ni un paso atrás. La prohibición de regresión en materia de derechos sociales, Buenos Aires, Del Puerto.

Góngora Mera, Manuel (2013). "Derecho a la salud y discriminación interseccional: Una perspectiva judicial de experiencias latinoamericanas". En: CléRICO, Laura, Liliana Ronconi y Martín Aldao, Tratado de Derecho a la Salud, Buenos Aires: Abeledo Perrot, pp. 133-159.

Guttman, Amy (2001). La educación democrática. Una teoría política de la educación. Barcelona: Paidós.

Krsticevic, Viviana (2006). "La tutela de los derechos sociales en el sistema interamericano". En: Yamin, Alicia (coord.). Derechos económicos, sociales y culturales en América Latina. Del invento a la herramienta. Centro Internacional de Investigaciones para el Desarrollo/Asociación Pro Derechos Humanos, México D.F.: Plaza y Valdés Editores, pp. 171-194.

Mosquera Quintero, Diana (2011). La salud como derecho. Estudio comparado sobre grupos vulnerables. Bogotá: Siglo del Hombre/Universidad ICESI/Red ALAS.

Nino, Carlos (2005). Fundamentos de Derecho Constitucional ( $3^{\mathrm{a}}$ reimp.). Buenos Aires: Astrea.

PARRA Vera, Oscar (2011). Justiciabilidad de los derechos económicos, sociales y culturales ante el Sistema Interamericano. México: Comisión Nacional de Derechos Humanos.

(2013). "La protección del derecho a la salud a través de casos contenciosos ante el Sistema Interamericano de Derechos Humanos". En: ClérICo, Laura, Liliana Ronconi y Martín Aldao. Tratado de Derecho a la salud. Tomo I. Buenos Aires: Abeledo Perrot, pp. 761-799. 
Ronconi, Liliana (2012). "Derecho a la salud: un modelo para la determinación de los contenidos mínimos y periféricos". Revista Salud Colectiva, 8(2): 131-149. Disponible en: <http://www.scielo.org.ar/pdf/sc/v8n2/v8n2a03.pdf>.

Rossi, Julieta y Víctor AвRAmovich (2009). "La tutela de los derechos económicos, sociales y culturales en el art. 26 de la Convención Americana sobre Derechos Humanos", Revista Estudios Socio-Jurídicos 9: 34-53.

Tomasevsky, Katarina (2004). El asalto a la educación Barcelona: Itermon Oxfam.

(2004a). Indicadores del derecho a la educación. Revista del Instituto Interamericano de Derechos Humanos 40: 341-388.

Scioscioli, Sebastián (2015). La educación básica como derecho fundamental. Implicancias $y$ alcances en el contexto de un Estado federal. Buenos Aires: Eudeba.

Von Bogdandy, Armin, Flávia Piovesan y Mariela Morales Antoniazzi (coord.) (2012). Igualdad y orientación sexual. El Caso Atala de la Corte Interamericana de Derechos Humanos y su potencial. México DF: Porrúa

\section{JURISPRUDENCIA}

Corte IDH. Caso "Cinco Pensionistas" vs Perú. Sentencia de 28 de febrero de 2003 (fondo, reparaciones y costas). Serie $\mathrm{C} \mathrm{N}^{\circ} 98$.

Caso Yean y Bosico vs. República Dominicana. Sentencia 8 de septiembre de 2005 (excepciones preliminares, fondo, reparaciones y costas). Serie $\mathrm{C} \mathrm{N}^{\circ} 130$.

Caso Kimel vs. Argentina. Sentencia de 2 de mayo de 2008 (fondo, reparaciones y costas). Serie $\mathrm{C} \mathrm{N}^{\circ} 177$.

. Caso Acevedo Buendía y Otros (“Cesantes y Jubilados de la Contraloría”) vs Perú. Sentencia de 1 de julio de 2009 (excepción preliminar, fondo, reparaciones y costas). Serie C N 198 .

Caso Comunidad Indígena Xákmok Kásek. vs. Paraguay. Sentencia de 24 de agosto de 2010 (fondo, reparaciones y costas). Serie C N 214.

. Caso Atala Riffo y niñas vs. Chile. Sentencia de 24 de febrero de 2012 (fondo, reparaciones y costas). Serie C No 239 .

Caso Forneron e Hija vs. Argentina. Sentencia de 27 de abril de 2012 (Fondo, Reparaciones y Costas). Serie C N 242 .

Caso Gonzales Lluy y otros versus Ecuador. Sentencia de 1 de septiembre de 2015 (excepciones preliminares, fondo, reparaciones y costas). Serie C N 298 .

\section{Observaciones Generales}

Comité DESC. Observación General N 3 "Derecho a la Educación". $21^{0}$ período de sesiones, 1999, U.N. Doc. E/C.12/1999/10.

Recibido: 19 de febrero de 2016 Aceptado: 28 de mayo de 2016 